\title{
The Study of Bending Forming Using Finite Element Discretization
}

\author{
SHEN Longzhang ${ }^{1, a}$, FAN Yujin ${ }^{1, b}$, HUAI Jianming ${ }^{1, c}$, HAN Teng ${ }^{1, d}$, WANG \\ Weida $^{1, e}$ and LIANG Ting ${ }^{2, f}$ \\ ${ }^{1}$ Faculty of Mechanical and Electrical Engineering, Kunming University of Science and Technology, \\ Kunming Yunnan, 650093, China \\ ${ }^{2}$ Faculty of Foreign Languages and Cultures, Kunming University of Science and Technology, \\ Kunming Yunnan, 650093, China \\ a shenlongzhang@126.com, b fanyujin@public.km.yn.cn, ${ }^{\mathrm{c}}$ saplinghuai@gmail.com, \\ d cupidisboy@126.com, ${ }^{\mathrm{e}}$ wangweida1002@163.com, ${ }^{\mathrm{f}}$ liangting1229@163.com
}

Keywords: Bending forming; Finite element method; Dynamic analysis; shape changing.

\begin{abstract}
In the bending forming process, it is well known that the relation of the forces and the strains. But it is inexplicit about the dynamic process. This paper analysed the bending forming dynamic process of the pure T2 copper. A finite element mesh is printed on the top end surface of the specimen by a hairline greasy pen. The dynamic process was carried out on a bending machine, and shot by a digital camera. The photos of forming process were processed in order to make the analysis explicitly. Through contrasted the processed photos of the different times, the shape changing could be observed clearly. And the pure T2 copper would be bended more easier in the later period process.
\end{abstract}

\section{Introduction}

Recent societal circumstances have led to new innovations for metal forming process, namely those in harmony with the environment[1]. Cold forming of copper is a group of very convenient and efficient manufacturing methods, which are successfully used in a number of industrial applications, including deep drawing, extrusion and bending[2]. The cold forming process in focus of this study is performed at ambient temperature with the use of a two-piece tool, a die and a punch. The forming starts from a solid metal blank that is placed in the die and forced by the high pressure from the punch to deform plastically into the new shape defined by the volume between the die and punch. The method has several advantages compared to othermethods: no scrapmaterial is produced, a decorative surface finish is achieved and many complex shapes may be formed [3,4]. But there are so much defect consist in this method such as forming limitations, spring-back and exterior quality [5].

Bending forming is a fast process, and a great number of products should be possible to form without interruption for service or exchange of tool. However, there is little research about its dynamic process. For instance, Zhan[5], Gollo[6], Li[7] and Zeng[8] all have employed the finite element analysis. There are many methods for measuring the strain of work piece, which are inconvenient for that between processes. In order to analyse of the principle, a simple and accurate method is need to develop[9, 10].

In this paper, for the purpose of accurate measuring the dynamic changing of the sepcimen, a finite element mesh is printed on the top end surface of the specimen by a hairline greasy pen. Then mesh plots were gotten from the photographs shot by the megapixel digital camera processed by the compile software. In the end, through contrasted the grid graphs of the dynamic process of the bending forming, it could be found that the pure T2 copper would be bended more easier in the later period process.

\section{The analytical method of bending forming process based on image}

There are many analytical methods of bending forming, the most extensive approach is finite element analysis through the computer. This computing method is more and more accurately, but also 
can't be compared to the photos of the sample. A digital camera installed on a bending machine to shot the specimen as shown in Fig. 1, and it has 1200000000 pixels. The nominal pressure of the bending machine is $300 \mathrm{kN}$. The bending angle was controlled by adjustment of the baffle in front of the specimen, and the pointer would be changed follow the displacement of the baffle, see in Fig. 1.So the pointer with the dial could indicate the angle of the bending forming. The radius of the punch is 8 $\mathrm{mm}$.

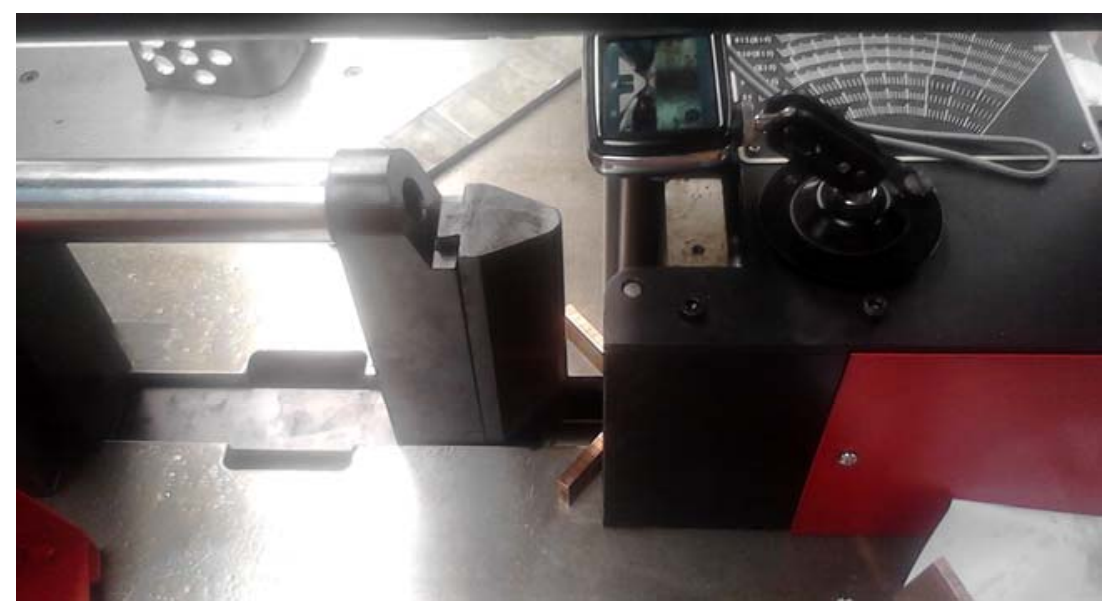

Fig. 1. Photography of the experimental facility

The workpiece material used is commercially available pure T2 copper. The component of pure T2 copper is summarized in Table.1, and mechanical property of it is summarized in Table. 2.

Table. 1. Component of pure T2 copper

\begin{tabular}{|c|c|}
\hline Element & Mass Fraction \\
\hline $\mathrm{Cu}$ and Ag & 99.90 \\
$\mathrm{Bi}$ & 0.001 \\
$\mathrm{Sb}$ & 0.002 \\
$\mathrm{As}$ & 0.002 \\
$\mathrm{Fe}$ & 0.005 \\
$\mathrm{~Pb}$ & 0.005 \\
$\mathrm{~S}$ & 0.005 \\
\hline
\end{tabular}

Table. 2. Mechanical property of pure T2 copper

\begin{tabular}{|c|c|}
\hline Item & Parameter \\
\hline Tensile Strength & $(\mathrm{Rm} / \mathrm{MPa}) \geqslant 295$ \\
Rockwell Hardness & $(\mathrm{HRF}) \geqslant 65$ \\
Elongation & $(\%) \geqslant 3$ \\
\hline
\end{tabular}

Copper is non-ferrous metal. The printed mesh can be distinguished well by using black greasy pen. The mesh's width is $2 \mathrm{~mm}$, and length is $5 \mathrm{~mm}$. The photography of the specimen is shown in Fig. 2 .

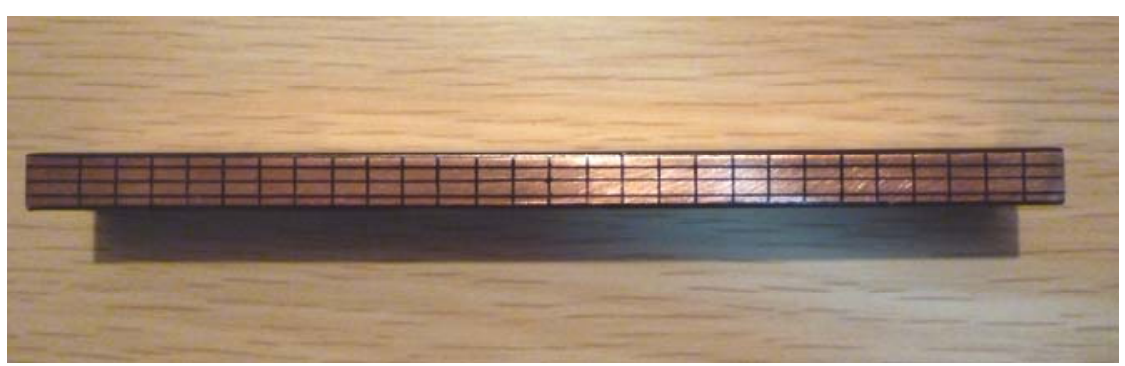

Fig. 2. Photography of the specimen

Dynamic measurement of the bending forming process and image processing 
Through some parts of the specimen were kept out by the moulds on the machine, the key parts were shot clearly. It is continuously in the course of filming, and the screenshots were come from the video shot by the camera. The bending forming process has lasted six seconds. So the interval of the screenshot was one second. And the photographs of the specimen per second as shown in Fig. 3.

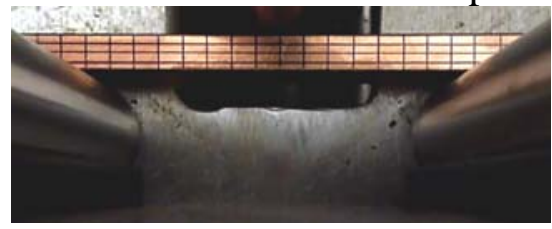

0s

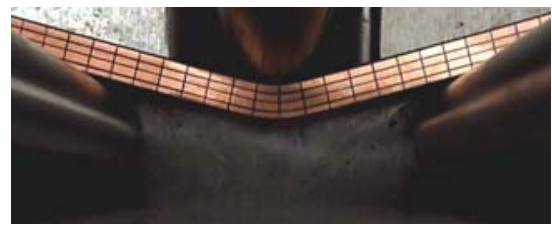

$2 \mathrm{~s}$

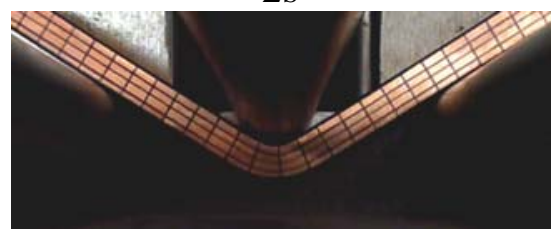

4s

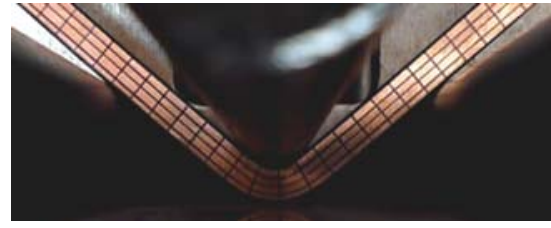

$6 s$

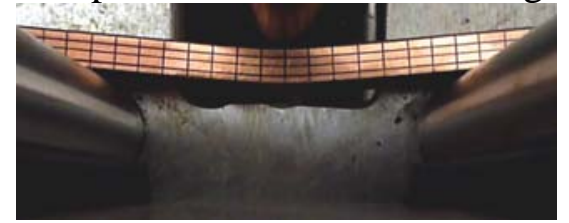

1s

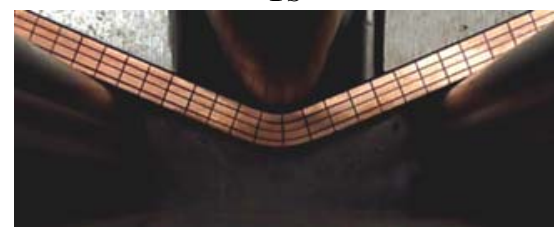

3s

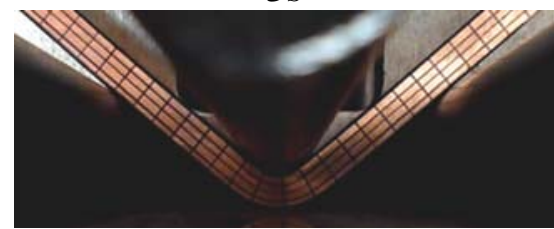

$5 s$

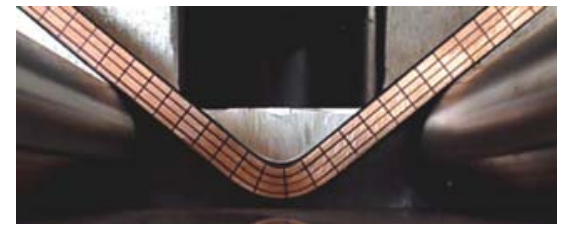

$7 \mathrm{~s}$

Fig. 3. Photographs of the specimen per second

The photographs as shown in Fig. 3 were processed by the compile software. In order to save space, the introduce of the software was removed. And the mesh plots which were outcome frome the image processing of the photographs shown in Fig. 4.
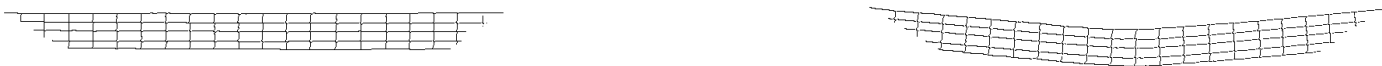

0s

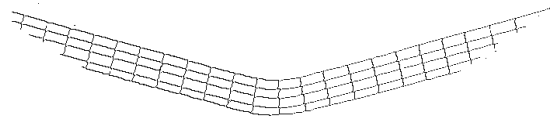

2s

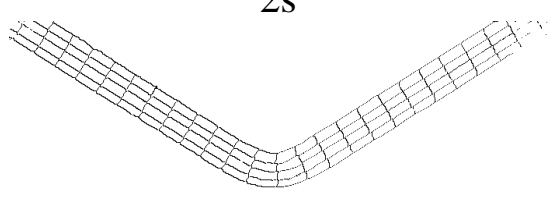

4s

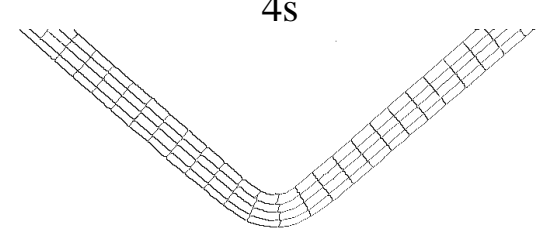

6s 1s

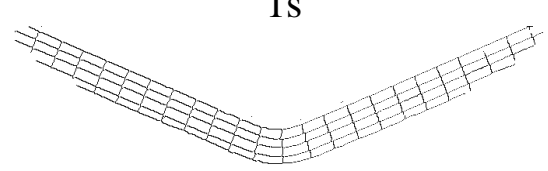

3s

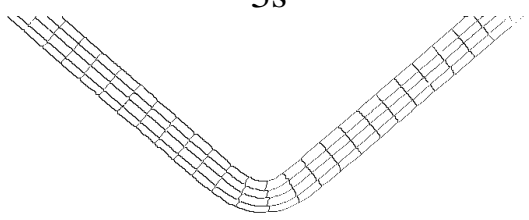

5s

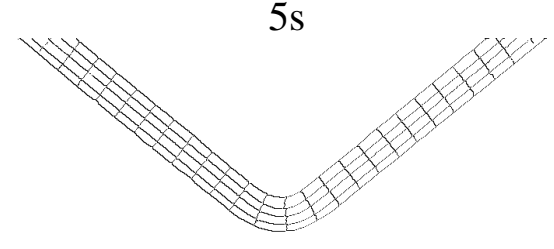

7s 
Fig. 4. Mesh plots of the specimen

By contrasted the mesh plots of the specimen per second shown in Fig. 4(0s, 1s, 2s, 3s, 4s, 5s, 6s, $7 \mathrm{~s}$ ), the form changing from the mesh in the time of $0 \mathrm{~s}$ to $1 \mathrm{~s}$ is smaller than that in $1 \mathrm{~s}$ to $2 \mathrm{~s}$. And the increment of the bending increased with the proceed of the bending forming. And if the mesh plots were analyzed unseasingly, more principles could be found out by the careful comparison of them. Although the mesh plots can't be contrast to the computing FEM in mesh density, it is the most real reporting of the specimen.

\section{Conclusions}

A. A finite element mesh is printed on the top end surface of the specimen by a hairline greasy pen. Through shot by a digital camera, and image processed, the tiny shape change of the specimen could be found out more easier. And the method introduced in this article could be a simple and feasible analytical approach in bending forming.

B. Through contrasted the grid graphs of the dynamic process of the bending forming, it could be found that the pure T2 copper would be bended more easier in the later period process.

\section{References}

[1] J. Heinrichs and S. Jacobson: Laboratory test simulation of galling in cold forming of aluminium. Wear. Vol. 267(2009), p. 2278.

[2] Akira Azushima, Shigeki Yoneyama and Hiroshi Utsunomiya: Coefficient of friction at interface of lubricated upsetting process. Wear. Vol. 286-287(2012), p. 3.

[3] Zhengkun Feng and Henri Champliaud: Modeling and simulation of asymmetrical three-roll bending process. Simulation Modelling Practice and Theory. Vol. 19 (2011), p. 1913.

[4] Haibo Li, Jun Chen and Jimmy Yang: Experimental and numerical investigation of laminated steel sheet in V-bending process considering nonlinear visco-elasticity of polymer layer. Journal of Materials Processing Technology. Vol. 212(2012), p. 36.

[5] Mei Zhan, Chuangguo Gu, Zhiqiang Jiang, et al..: Application of ductile fracture criteria in spin-forming and tube-bending processes. Computational Materials Science. Vol. 47(2009), p. 353.

[6] M. Hoseinpour Gollo, S.M. Mahdavian and H. Moslemi Naeini: Statistical analysis of parameter effects on bending angle in laser forming process by pulsed Nd: YAG laser. Optics \& Laser Technology. Vol. 43(2011), p. 475.

[7] L. Li, Q. Zhou, Y.Y. Zhou and J.G. Cao: Numerical study on the size effect in the ultra-thin sheet's micro-bending forming process. Materials Science and Engineering. A. Vol. 499(2009), p. 32. [8] Jun Zeng, Zhaoheng Liu and Henri Champliaud: FEM dynamic simulation and analysis of the roll-bending process for forming a conical tube. Journal of Materials Processing Technology. Vol. 198(2008), p. 330.

[9] Sutasn Thipprakmas and Wiriyakorn Phanitwong: Process parameter design of spring-back and spring-go in V-bending process using Taguchi technique. Materials \& Design. Vol. 8-9(2011), p. 4430.

[10] Janina Adamus and Piotr Lacki: Forming of the titanium elements by bending. Computational Materials Science. Vol. 50(2011), p. 1305. 